\title{
The geography of music preferences
}

\author{
Charlotta Mellander ${ }^{2} \cdot$ Richard Florida $^{3} \cdot$ Peter J. Rentfrow $^{1} \cdot$ \\ Jeff Potter 4
}

\begin{abstract}
Considerable attention has been paid to America's political and economic divides. These divides revolve around class and location, with more affluent, more educated and denser places leaning more open-minded and liberal and less affluent, less educated and less dense places leaning more conservative. We contend that such divides are also reflected and reinforced by preferences, attitudes and predispositions for culture. More specifically we argue that Americans' preferences for music will reflect dimensions of these political and economic divides. To test this proposition, our research examines the geographic variation of five key categories of music preferences across 95 of the largest US metropolitan areas. We use factor analysis to identify and map geographic variation of musical preferences, and we use both bivariate correlation analyses and regression analysis to examine the associations between metro-level musical preferences and key economic, demographic, political, and psychological variables. We find that musical preferences generally reflect and reinforce America's broader economic and political divides.
\end{abstract}

Charlotta Mellander

charlotta.mellander@ju.se

Richard Florida

florida@rotman.utoronto.ca

Peter J. Rentfrow

pjr39@cam.ac.uk

Jeff Potter

jeff@thebigfiveproject.com

1 Department of Psychology, University of Cambridge, Cambridge, UK

2 Jönköping International Business School, Jönköping University, Jönköping, Sweden

3 Martin Prosperity Institute, Rotman School of Management, University of Toronto, Toronto, Canada

4 Atof Inc., Cambridge, MA, USA 
Keywords Music preferences - Geography - Socioeconomic structures

\section{Introduction}

There is a long line of research and theory on the class and geographic bases of political and cultural divides. In the main, this literature finds that denser, more affluent and educated locations are more open-minded and politically liberal and that less dense, less affluent and less educated places skew more traditional, more closer-minded and more conservative. Here we argue that these geographic divides are not only economic and political but reflect and are reinforced by cultural preferences, attitudes and predispositions.

Indeed, there is a somewhat older vein of research and theory that identifies both the geographic variation in cultural preferences and connects that variation to underlying economic and political divides. Zelinsky (1974) examined cultural differences in the USA using magazine subscriptions and found a strong divide between the preferences of residents of cities and metro areas with higher concentrations of professional, white-collar workers, college-educated residents, and higher levels of diversity, on the one hand and those with high shares of bluecollar workers, and less advantaged residents and low levels of diversity. Fox and Wince (1975) found that individuals from small farm towns preferred folk, rock, and country music, while individuals from larger regions preferred jazz and blues music.

Weiss (1988) found a divide between a bi-coastal preference for theater and public broadcasting on the one hand and a preference for hunting, fishing and conservative radio in the Midwest and Southeast.

This research focuses on the consumption of books, magazines, newspapers, film and television (Zelinsky 1974; Weiss 1988). Our research examines the extent to which preferences for music both reflects these divides and can help us understand them. Indeed, music plays a central role in culture and cultural consumption. The typical American, for example, listens to roughly $18 \mathrm{~h}$ of music in an average week (Motion Picture Association of America 2007). In other words, people on average spend roughly a fifth of their waking hours with music playing. Music is a very heterogeneous art form. There are myriad musical styles and genres from classical to jazz and blues, $\mathrm{R} \& \mathrm{~B}$ and hip-cop, country and religious, rock and pop. Furthermore, research shows that people's tastes and preferences for music vary widely not just across demographic groups but also across cities and geographic areas.

More recent research identifies connections between music preferences and socioeconomic class, with upper class and well-educated individuals preferring "high-brow" music genres, such as classical, opera, and big band, and working class and less educated individuals preferring "low-brow" music, such as country, gospel, and rap (Katz-Gerro 1999; Mark 1998; Van Eijck 2001). Musical preferences have been linked to personality factors as well as (Colley 2008; Delsing et al. 2008; Dunn et al. 2012; Rentfrow and Gosling 2003). Several studies indicate that individuals with strong preferences for sophisticated musical styles, 
like classical, opera, or jazz, score high on psychological measures of creativity, curiosity, intelligence, and political liberalism (Rentfrow and Gosling 2003). There is also evidence that people who enjoy intense styles of music, like rock, heavy metal, and punk, score high on psychological measures of thrill-seeking, openness, and also value freedom and independence (Rentfrow and Gosling 2003, 2006; McNamara and Ballard 1999; Zweigenhaft 2008).

Our research examines the geographic variation in preferences for popular music and the economic and political factors that account for such variation. Drawing from previous research in psychology (e.g., Delsing et al. 2008; North and Hargreaves 1996; North et al. 1999; Rentfrow and Gosling 2003; Zweigenhaft 2008), our research examines geographic variation in five music-preference dimensionsreferred to by the acronym MUSIC - mellow, unpretentious, intense, sophisticated and contemporary (Rentfrow et al. 2011).

The central hypothesis is that geographic variation in music preferences reflects and reinforces related political and economic divides by class and geography. As noted above, we believe that geographic preferences for music will vary based on density and socioeconomic class, as measured by income, education and occupation. We also test for the role of other demographic factors such as race and marital status as well as for personality factors which the psychology literature has found to play a role in the variation in music preferences. The research is based on a large nationwide survey of approximately 120,000 individuals that assessed individual differences in music preferences. We map music preferences by metro region, and provide both a correlation analysis and a regression analysis of music preferences and economic, demographic and psychological variables across 95 US metros with a population of 500,000 or more.

The key findings provide support for the hypotheses. Music preferences vary geographically in line with America's broader economic and political divide. Broadly speaking, two musical types-sophisticated and contemporary-are associated with more affluent, more educated, more knowledge-based places that are also denser, more diverse, and politically liberal. Two other musical typesunpretentious and intense-are associated with less advantaged, less educated, more working class places that are more politically conservative and have larger white populations. Thus, overall, we find that the geography of music preferences across US metropolitan areas reflects and reinforces broader divides of economic, class and politics.

\section{Data, variables and methodology}

Our study examines the geographic divide in music preferences across 95 of the largest US metropolitan regions. We expect that: (1) music preferences will vary substantially across metro regions, and (2) that such variation will reflect and be shaped by regional variation in underlying economic and political divides. To test these claims, we employ data from a large-scale Internet survey involving approximately 120,000 individuals. 92,000 of these live in big metropolitan regions 
with more than 500,000 in population, and these regions are the focus of our analysis.

We assess geographic variation in music preference across five broad categories of types of music: mellow, unpretentious, sophisticated, intense, and contemporary, referred to the convenient moniker "MUSIC" (Rentfrow et al. 2011, 2012). Mellow reflects music that is romantic, relaxing, unaggressive, sad, slow, and quiet; unpretentious is relaxing, unaggressive, soft, and acoustic; sophisticated is inspiring, intelligent, complex, and dynamic; intense is distorted, loud, aggressive; and contemporary is percussive and electric.

We use factor analysis to identify the geographic structure of these broad musical types. We then map the geographic variation in each of the five major types of music. We also conduct bivariate correlation analysis and regression analysis of the associations between these music preferences and key economic, demographic, political, and psychological variables.

\section{Primary data}

The music preferences data were collected as part of an ongoing study of music preferences involving volunteers assessed over the World Wide Web (http://www. outofservice.com/music-personality-test/). The web site is a non-commercial, advertisement-free web site containing a variety of psychology measures. Potential respondents could find out about the site through several channels, including search engines, or unsolicited links on other web sites. The data reported in the present research were collected between 2001 and 2013.

Respondents volunteered to participate in the study by "clicking" on the musicpreference test icon and were then presented with a series of questions about their music preferences, personalities, demographic characteristics, and place of residence. After responding to each item and submitting their responses, participants were presented with feedback about the music preferences based on their responses to the items.

\subsection{Participants}

As in all studies that collect data from individuals over the Internet, there is the possibility that respondents may complete a survey multiple times. Repeat responding has the potential to produce unreliable and misleading results so it was necessary to remove data from potential repeat responders.

\subsection{Screening}

Several criteria were used to eliminate repeat responders. First, one question included in the survey asked: "Have you ever previously filled out this particular questionnaire on this site?" If respondents reported completing the questionnaire before, their data were excluded. Second, IP addresses were used to identify repeat responders. If an IP address appeared two or more times within a 1-h period, all 
responses were deleted. Third, if an IP address appeared more than once in a time span of more than $1 \mathrm{~h}$, consecutive responses from the same IP address were matched on several demographic characteristics (gender, age, ethnicity) and eliminated if there was a match. Finally, only respondents who indicated that they lived in a metropolitan region with more than 500,000 inhabitants were included. ${ }^{1}$

\subsection{Demographics}

Implementation of these criteria resulted in complete data for 119,316 individuals, out of which 91,948 respondents live in metropolitan regions with more than 500,000 individuals. The median age of respondents is 24 years ( $\mathrm{SD}=11.04$ years). Of those who indicated, $59 \%$ are female, $75 \%$ are white, $6 \%$ are African American; $7 \%$ are Asian; and 7\% are Latino. ${ }^{2}$ Of those who provided information about their social class, $21 \%$ said that are working class; $20 \%$ lowermiddle class, $39 \%$ middle class, $17 \%$ upper-middle class, and $2 \%$ were upper class.

\subsection{Representativeness}

To ensure that each metropolitan region was fairly represented, we correlated the percentage of total respondents from each metropolitan region in our sample with the percentage of the total US population for each metro using data from the US Census Bureau for the year 2010. The percentage of respondents from each metro in our sample was directly proportional to the 2010 US Census Bureau's estimates of the population of each metro, $r=.96 .^{3}$

Past research on Internet-based surveys suggests that minority groups are vastly underrepresented on the Internet (Lebo 2000; Lenhart 2000). Therefore, to determine whether our sample overrepresented individuals from particular racial groups or social classes, we correlated the percentage of respondents for each group from the Internet sample with the percentage of the population of that group within each metro. For example, we correlated the percentage of Asian respondents from each metro with the US Census Bureau's estimate of the percentage of Asians in each metro. The correlations for African Americans, Asians, Latinos, Whites, and "Other" ethnicities, respectively, were .92, .94, .95, .74, and .67, all $p$ s $<.001$.

Overall, these analyses indicated that our Internet-based sample was generally representative of the population at large. Indeed, with the exception of "Other" ethnicities, the racial composition of our sample matched almost perfectly the US Census Bureau's population estimates. It appears as though our sample underrepresented individuals from lower and upper classes, but the sample is still far more

\footnotetext{
1 We exclude metropolitan regions with less than 500,000 in population, to assure that we have enough observations in each region. However, we ran the analysis for all metropolitan regions as well, even though the number of individuals that took the survey sometimes was relatively low.

2 The equivalent numbers for the 119,316 individuals across all metros were; $5 \%$ African American; $6 \%$ Asian; 6\% Latino; 77\% White; 5\% "Other" for race; 23\% working class, $21 \%$ lower-middle class, 38\% upper-middle class, and $2 \%$ upper class for class.

${ }^{3}$ We are still aware of that the representativeness is not perfect, as we, e.g., have a younger average age in our examined group of individuals than what would be the case for real.
} 
representative of the US population than are most psychological studies that rely on convenience samples (Gosling et al. 2004).

\subsection{Identifying music preferences}

Music preferences were measured using the revised version of Rentfrow and Gosling's (2003) Short Test of Music Preferences (STOMP-R). The STOMP-R is a 21-item survey designed to measure individual differences in musical preferences. Using a rating scale with endpoints at 1 (Dislike) and 7 (Like), respondents indicate the degree to which they like each of the following music genres: alternative, bluegrass, blues, classical, country, electronica, folk, gospel, heavy metal, rap, jazz, new age, opera, pop, punk, reggae, religious, rock, soul/R \& B, funk, and world (Rentfrow and Gosling 2003).

\section{Secondary data}

We use a variety of secondary data to examine the relationships between music preference and regional economic, demographic, political, cultural and social psychological characteristics.

\subsection{Economic}

\subsubsection{Economic conditions and divides}

We use several indicators of metropolitan economic conditions and divides, including wages and salaries, and gross regional product (GRP) per capita (GRP). These data are for 2010 and come from the US Census, Bureau of Labor Statistics and the US Bureau of Economic Analysis. We also examined wage or salary income, including net self-employment income from the 2010 US Census, as well as average earning per hour and hours worked per week based on the 2010 Bureau of Labor Statistics.

\subsubsection{Class}

We use two key measures of socioeconomic class.

Education The first is education. This is based on adults with a bachelor's degree or more and is based on the 2008-2010 U.S. Census.

Occupation The second is occupation. We evaluate the share of workers across three major occupational or class categories (see Florida 2002). The creative class makes up a third of the workforce and includes workers in occupations such as computer and math occupations; architecture and engineering; life, physical, and social science; education, training, and library positions; arts and design work; and selected entertainment, sports, and media occupations. The working class comprises $20 \%$ of the workforce and includes workers in traditional blue-collar jobs in 
manufacturing, construction and transportation and material moving occupations. The data are from the Bureau of labor Statistics for 2010.

\subsection{Political divides}

We use the metro-level share of votes in the 2012 US Presidential election for Obama and Romney as proxies for liberalism and conservativism. It is worth pointing out that despite the differences in electoral outcomes for the 2008, 2012 and 2016 Presidential elections, the metro-level vote for liberal (Democrat) and conservative (Republican) candidates are correlated are roughly the .0 .90 level. The data are from the Office of the Clerk, US House of Representatives.

\subsubsection{Education}

We also examined educational attainment or "human capital," measured as the share of the labor force with a university degree of 3 years or more, taken from the 2008-2010 US Census.

\subsubsection{Demographic factors}

We also include a series of demographic data.

Population and density We examine both population size and populationweighted density, which takes into account density based on distance from the city center. Both variables are from the ACS US Census data for the year 2010.

Race We include the major categories of white, black and Latino/Hispanic share of the population as well as the share of the population made up of immigrants. These variables are from the 2008-2010 US Census.

Marital status We examine several indicators, including the share of single households, married share of the population, the share of 15- to 19-year-old men and women that are married, and the share of the population that is divorced. These variables are also from the 2008-2010 Census.

\subsubsection{Psychology}

We include several variables to account for variation in psychological factors.

Personality Personality is conceptualized in terms of the Big Five, which comprises five broad dimensions of personality: Extraversion, Agreeableness, Conscientiousness, Neuroticism, and Openness. Metropolitan-level scores for each big-five domain were available from Rentfrow and Gosling (2003).

Tolerance We include two indicators of tolerance. The gay index is a location quotient for gay and lesbian households. The bohemian index is a location quotient for arts and design related fields. Both variables are based on data from the 2010 US Census. 
Well-being Our indicator of well-being is takes into account; emotional health, work quality, basic access, healthy behavior, physical health and life evaluation. It based on 2010 survey data from the Gallup Organization.

\section{Methods}

We were interested in metro-level trends in musical preferences, so we aggregated individual-level preferences for each genre among respondents who reported living in each of the metropolitan areas. Then we examined the factor structure of the metro-level musical preferences. Specifically, we conducted a principle components analysis with varimax rotation on the metro-level music preferences to determine whether preferences can be characterized in terms of a set of meaningful dimensions. We used the results from the factor analysis to map geographic variation in musical preferences. We then used bivariate correlation analysis to relate the variation in these music preferences to key economic, social, political and psychological variables described above, followed by a regression analysis. Because of the large number of explanatory variables, the relatively low number of observations $(N=95)$, and the high level of linearity between the explanatory variables, we run a principal component analysis for the economic, social, political and psychological factors to reduce the number of explanatory variables and avoid issues with multicollinearity.

\section{Findings}

\subsection{Metro-level music-preference dimensions}

We begin by examining the variation in music genre preferences at the metro level of analysis. Previous research on musical preferences has focused on the individual level, and because the present work is focused on the aggregate level, it was important that we determine whether the same factor structure exists at the regional level. We calculated the metro-level mean scores for each music genre.

On average, rock and alternative were the two music genres most highly ranked at the metro level, followed by pop and classical. The least liked music genres were religious, gospel, opera, and bluegrass. Religious, bluegrass, and country music genres had the largest standard deviations across regions, while rock, alternative, oldies and new age preferences varied the least. (The detailed descriptive statistics is provided in Appendix Table 6).

To identify metro-level music preferences, we conducted a principal components analysis with varimax rotation. This analysis identified five components with eigenvalues greater than one, the scree plot showed an 'elbow' at roughly six factors, and each factor comprised items with few cross-loading genres. All in all, the factors resembled the MUSIC preference model observed in previous research at the individual level (Rentfrow et al. 2011, 2012). To formally test the extent to which the metro-level factor structure captured the individual-level MUSIC factors, 
we examined the factor congruence coefficients between the metro-level factor loadings and individual-level factor loading reported by Bonneville-Roussy et al. (2013). The results from this analysis strongly suggested that the five musicpreference factors were virtually identical to the MUSIC factors observed in individual-level research on music preferences. Indeed, the factor congruence coefficients for each factor exceeded Lorenzo-Seva and ten Berge's (1977) threshold of .85 (factor congruence coefficients $=.91, .87, .92, .93$, and .92, M, $\mathrm{U}, \mathrm{S}, \mathrm{I}$, and $\mathrm{C}$, respectively).

The metro-level factor structure is shown in Table 1. As can be seen in the first data column, the genres with their primary loadings on the Mellow factor are electronica and new age. The genres with primary loadings on the Unpretentious factor are religious, country, gospel, and pop. The genres with the largest loadings on the Sophisticated factor are folk, bluegrass, blues, jazz, opera, classical, and world. The genres with the largest loadings on the Intense factor are heavy metal, rock, punk, and alternative. The genres with the highest loadings on the Contemporary factor are rap, soul, funk, and reggae. All in all, the patterns of factor loadings appear quite similar to those observed in research at the individual level (Bonneville-Roussy et al. 2013; Delsing et al. 2008; Rentfrow and Gosling 2003; Rentfrow et al. 2011). (The detailed results from the Principle Component Analysis are provided in Appendix Table 7).

\section{Mapping the geography of music preferences}

We now turn to the geographic distribution of music preferences. To get at this, we computed metro-level factor scores to represent each metropolitan region's degree of preference for each of the MUSIC factors. The maps below show the geographic distribution for each of the five music-preference dimensions based on the factor analysis. The color scheme in the maps is based on the generated genre score from the principle component analysis. The higher the score, the stronger is the average preference for this specific music genre.

\subsection{Mellow}

Figure 1 maps mellow music preferences by metropolitan region. The top ten metros on this dimension are Provo-Orem, UT; McAllen-Edinburg-Mission, TX; Salt Lake City, UT; El Paso, TX; Ogden-Clearfield, UT; Fresno, CA; Palm Bay-

Table 1 Generated music genres from the PCA

\begin{tabular}{ll}
\hline Genre & Types of Music \\
\hline Mellow & Electric, new age \\
Unpretentious & Religious, country, gospel, pop \\
Sophisticated & Folk, bluegrass, blues, jazz, opera, classical, world \\
Intense & Heavy metal, rock, punk, alternative \\
Contemporary & Rap, soul, funk, reggae \\
\hline
\end{tabular}




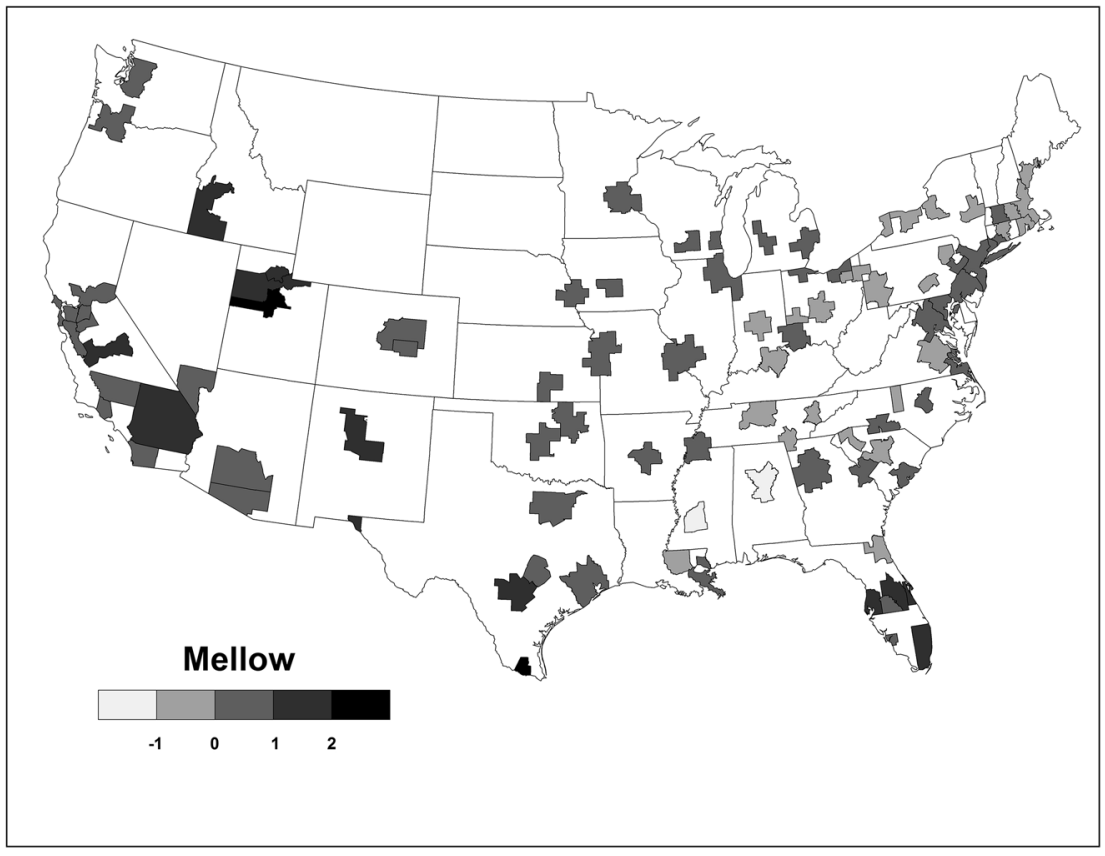

Fig. 1 Metro-Level Preferences for Mellow Music

Melbourne-Titusville, FL; Boise-Nampa, Idaho; Tampa-St. Petersburg-Clearwater, FL; Albuquerque, NM; and Miami-Ft. Lauderdale-Pompano Beach, FL.

\subsection{Unpretentious}

Figure 2 maps unpretentious music preferences by metropolitan region. The top ten metros on this dimension are Jackson, MS; Charleston-North Charleston-Summerville, SC; Little Rock-North Little Rock-Conway, AR; Memphis, TN-MS-AK; Oklahoma City, OK; Chattanooga, TN-GA; Birmingham-Hoover, AL; GreenvilleMauldin-Easley, SC; Provo-Orem, UT; and San Antonio, TX.

Unpretentious metros are mainly clustered in the traditional south, Mississippi, South Carolina, Arkansas, Tennessee, Georgia, Alabama and Texas as well as Utah.

\subsection{Sophisticated}

The map of metropolitan-wide preferences for sophisticated music is plotted in Fig. 3. The top ten metros on this dimension are Austin-Round Rock, TX; San Francisco-Oakland-Fremont, CA; Jackson, MS; Greensboro-High Point, NC; Madison, Wisconsin; Rochester, NY; Columbia, SC; Charleston-North Charleston-Summerville, SC; Nashville-Davidson-Murfreesboro-Franklin, TN; and Albuquerque, NM. 


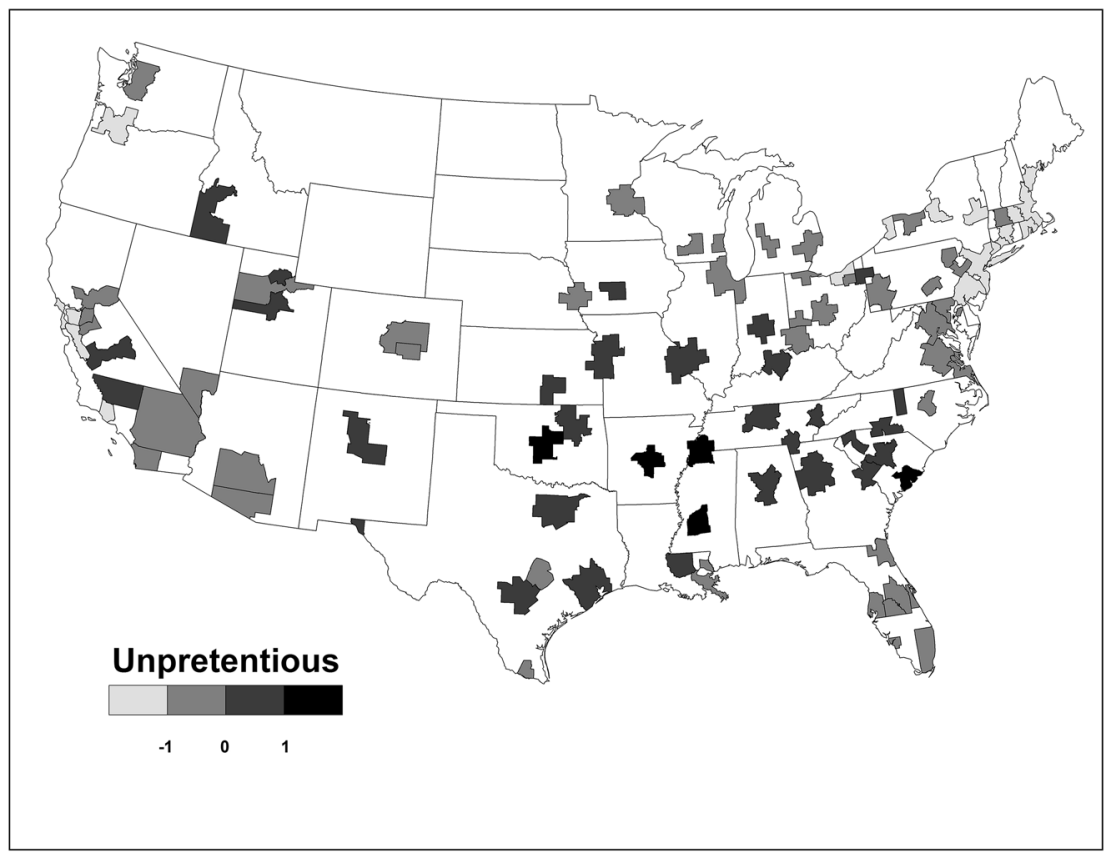

Fig. 2 Metro-Level Preferences for Unpretentious Music

Sophisticated metros are mainly clustered in the Sun Belt and West. Austin is first and San Francisco second, while Nashville (a leading center for music production) is ninth.

\subsection{Intense}

The map of preferences for intense music is shown in Fig. 4. The top ten metros on this dimension are Scranton-Wilkes-Barre, PA; Chattanooga, Tennessee; Las Vegas-Paradise. NV; Youngstown-Warren-Boardman, OH-PA; Greenville-Mauldin-Easley, SC; Albuquerque, NM; Portland-South Portland-Biddeford, ME; Colorado Springs, CO; Allentown-Bethlehem-Easton, PA-NJ; and Albany-Schenectady-Troy, NY.

Intense music is more broadly distributed with clusters across the Northeast, Midwest, South and West.

\subsection{Contemporary}

The map of preferences for contemporary music is shown in Fig. 5. The top ten metros on this dimension are Charleston-North Charleston-Summerville, SC; San Francisco-Oakland-Fremont, CA; Modesto, California; Richmond, VA; Des Moines-West Des Moines, IA; Orlando-Kissimmee, FL; Omaha-Council Bluffs, NE-IA; Memphis, TN-MS-AK; Birmingham-Hoover, AL; and Rochester, NY. 


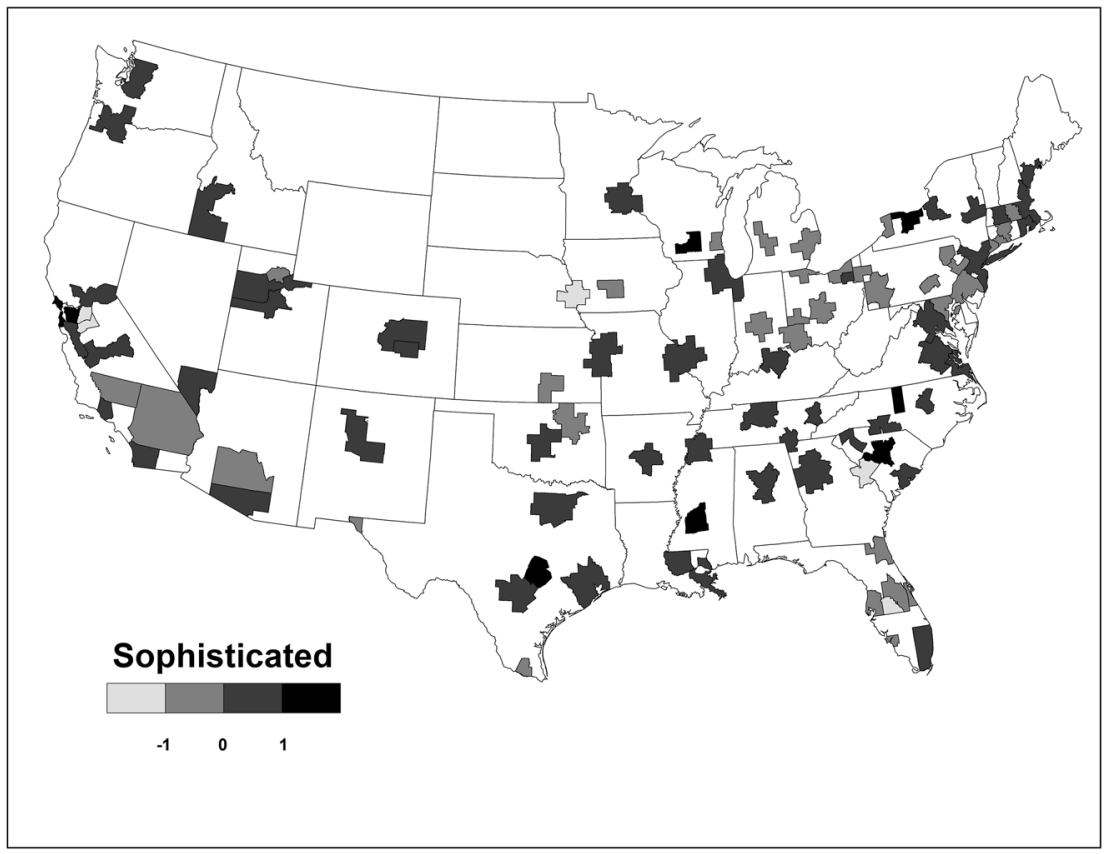

Fig. 3 Metro-Level Preferences for Sophisticated Music

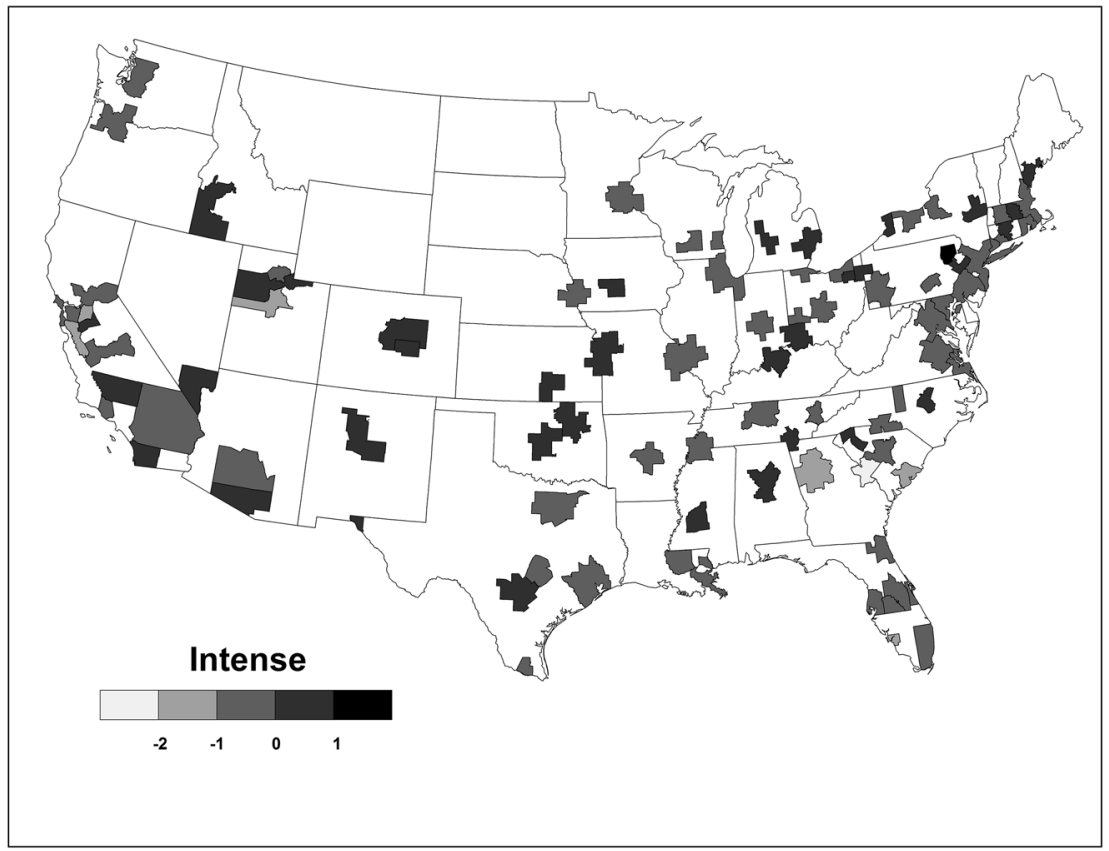

Fig. 4 Metro-Level Preferences for Intense Music 


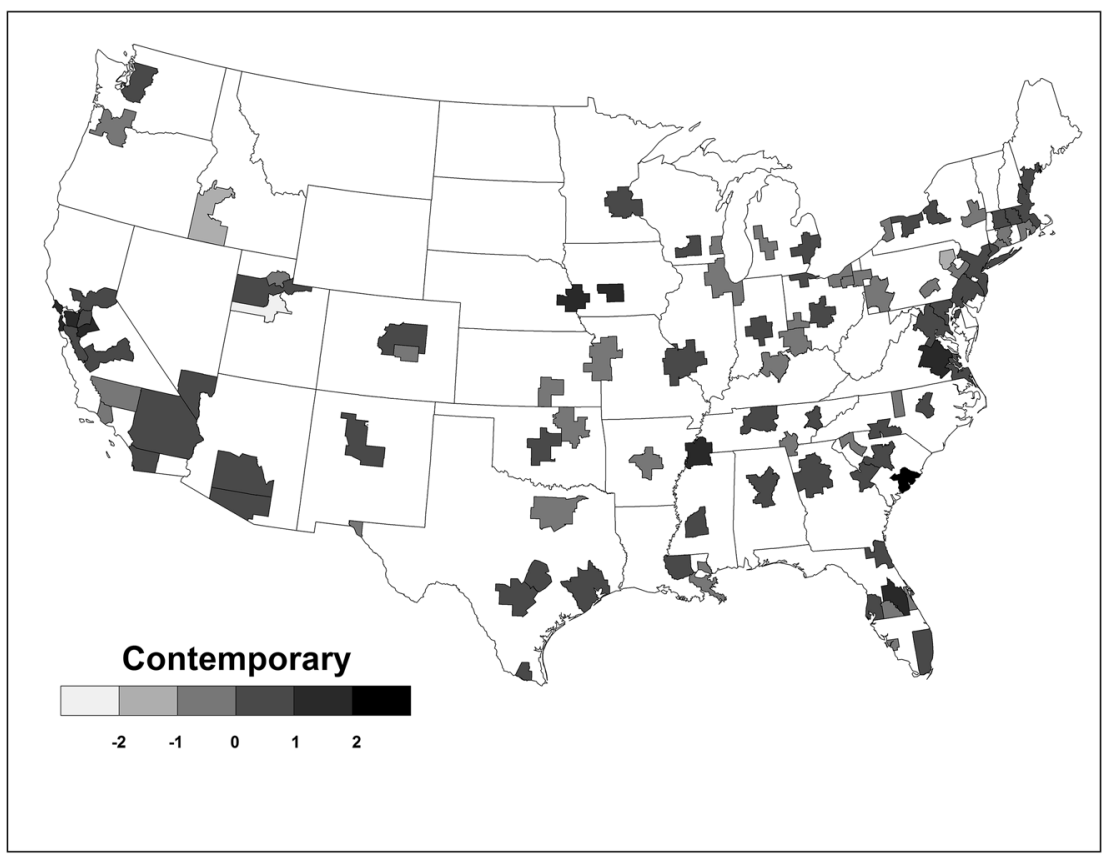

Fig. 5 Metro-Level Preferences for Contemporary Music

Leading contemporary music metros are located in the South and West, especially California and Iowa as well as the Northeast.

\section{Correlation analysis}

The maps of the MUSIC preference dimensions reveal interesting geographic patterns: But how meaningful are those differences, and what underlying factors are they associated with? To develop a better understanding the factors that are associated with these observed regional difference, we conducted a correlation analysis relating each of the five major music-preference factors to key economic, social, demographic, political and psychological variables. The summary results of the correlation analysis are displayed in Table $2 .^{4}$ A more detailed correlation results table is provided in Appendix.

\subsection{Mellow}

The correlations for Mellow music are reported in the first data column of Table 3. Metros with comparatively strong preferences for Mellow music had large shares of the Hispanic people $(r=.62)$, large shares of foreign born $(r=.52)$, and low shares

\footnotetext{
${ }^{4}$ We also re-ran the same analysis at the state level which generated very similar results.
} 
Table 2 Summary table for correlations*

\begin{tabular}{|c|c|c|c|c|}
\hline Mellow & Unpretentious & Sophisticated & Intense & Contemporary \\
\hline Hispanic (+) & Religiosity (+) & $\begin{array}{l}\text { Human capital } \\
\qquad(+)\end{array}$ & White $(+)$ & Gay index $(+)$ \\
\hline $\begin{array}{l}\text { Single household } \\
(-)\end{array}$ & Average wage $(-)$ & Gay index $(+)$ & Neuroticism (+) & White (- ) \\
\hline $\begin{array}{l}\text { Married age } 15-19 \\
(+)\end{array}$ & $\begin{array}{l}\text { Population density } \\
\quad(-)\end{array}$ & Well-being $(+)$ & $\begin{array}{l}\text { Divorce share } \\
(+)\end{array}$ & $\begin{array}{l}\text { Romney votes } \\
\qquad(-)\end{array}$ \\
\hline Foreign born $(+)$ & Income per cap $(-)$ & $\begin{array}{l}\text { Creative class } \\
(+)\end{array}$ & Agreeable $(-)$ & Obama votes $(+)$ \\
\hline Black $(-)$ & Romney votes (+) & Openness (+) & Wage per h $(-)$ & $\begin{array}{l}\text { Married share } \\
(-)\end{array}$ \\
\hline $\begin{array}{l}\text { Population density } \\
(+)\end{array}$ & Obama votes $(-)$ & Bohemians (+) & Single $(+)$ & Black (+) \\
\hline Married share $(+)$ & Agreeableness (+) & GRP per cap $(+)$ & $\begin{array}{l}\text { Foreign born } \\
(-)\end{array}$ & GRP per cap $(+)$ \\
\hline Neuroticism $(-)$ & $\begin{array}{l}\text { Conscientiousness } \\
(+)\end{array}$ & $\begin{array}{l}\text { Income per cap } \\
(+)\end{array}$ & $\begin{array}{l}\text { Average wage } \\
(-)\end{array}$ & Population (+) \\
\hline Openness $(+)$ & Working class $(+)$ & White $(-)$ & Gay index $(-)$ & Foreign born $(+)$ \\
\hline Well-Being $(+)$ & Wage per $\mathrm{h}(-)$ & Wage per $\mathrm{h}(+)$ & & Religiosity (- ) \\
\hline Income per cap $(+)$ & $\begin{array}{l}\text { Married age } 15-19 \\
(+)\end{array}$ & $\begin{array}{l}\text { Working class } \\
(-)\end{array}$ & & Wage per $\mathrm{h}(+)$ \\
\hline \multirow[t]{11}{*}{ Gay Index (+) } & Black (+) & & & $\begin{array}{l}\text { Income per cap } \\
(+)\end{array}$ \\
\hline & Human capital (- ) & & & \\
\hline & Bohemians (- ) & & & \\
\hline & Creative class $(-)$ & & & \\
\hline & Foreign born $(-)$ & & & \\
\hline & Population (- ) & & & \\
\hline & Divorce share $(+)$ & & & \\
\hline & Gay index $(-)$ & & & \\
\hline & GRP per cap $(-)$ & & & \\
\hline & $\begin{array}{l}\text { Work h per week } \\
(+)\end{array}$ & & & \\
\hline & White $(-$ ) & & & \\
\hline
\end{tabular}

*We display the strongest correlations of 0.2 or above. For detailed results, see Table 8 in Appendix

of the black and African American population $(r=-.39)$. These metros also had low shares of single households $(r=-.62)$, and are places where both men and women marry younger $(r \mathrm{~s}=-.40,-.54$, share of young men and women that are married, respectively). Mellow music metros also tend to have higher population densities $(r=.38)$. Mellow music preferences are more modestly correlated with well-being and working class occupational structures, and negatively associated with per capita income $(r=-.23)$. 
Table 3 Descriptives of extracted factors for metro socioeconomic characteristics

\begin{tabular}{ll}
\hline Factor & Descriptive of factor \\
\hline 1 & Affluent, knowledge based, creative, diverse, population dense \\
2 & More Hispanics and foreign born, marries early, many single households \\
3 & Democrats, less religious, lower shares of marriage \\
4 & Agreeable and conscientious, but less neurotic \\
5 & More blacks and fewer whites \\
6 & Higher divorce shares and work more hours \\
7 & Extroverts \\
\hline
\end{tabular}

\subsection{Unpretentious}

The correlations for Unpretentious music are shown in the second data column. The strongest correlation by far is for religion $(r=.80)$. Unpretentious music preferences are also significantly associated with working class occupations $(r=.48)$ and negatively associated with the creative class $(r=-.36)$ as well as the share of college graduates $(r=-.37)$. Unpretentious preferences are also related to political preferences (being positively correlated with Republican votes in the 2012 election $(r=.54$, and negatively associated with Democratic votes $r=-.55)$. Unpretentious music metros tend to be less well-off economically, with negative correlations to average wage $(r=-.59)$, income per capita $(r=-.56)$, wage per hour $(r=-.44)$, and GRP per capita $(r=-.27)$. Unpretentious preferences are associated with larger black populations $(r=.39)$. Unpretentious metros have lower levels of foreign-born populations $(r=-.34)$, bohemians $(r=-.39)$, and gays and lesbians $(r=-.28)$. Unpretentious metros have fewer single households $(r=-.19)$ and more men $(r=.22)$ and women $(r=.40)$ who marry young. In terms of personality, unpretentious metros are high in agreeableness and conscientiousness (both $r=.48$ ).

\subsection{Sophisticated}

The correlations for Sophisticated music are listed in the third data column in Table 3. Metros with preferences for sophisticated music have higher levels education (college graduates, $r=.45)$ and of the creative class $(r=.34)$. These metros also have higher levels of gays and lesbians ( $r=.43$ to the Gay Index), and lower shares of white population $(r=-.22)$. Sophisticated preferences are also related to income and affluence though more modestly, with positive correlations to economic output per capita $(r=.27)$ income $(r=. .22)$ and hourly earnings $(r=.22)$, as well as to overall well-being $(r=.36)$. In terms of personality, sophisticated preferences at the metro level are positively associated with openness personalities $(r=.43)$. 


\subsection{Intense}

The correlations for Intense music are provided in column four of Table 3. Intense music preferences were associated with larger concentrations of white residents $(r=35)$, smaller shares of black residents $(r=-.21)$, and smaller shares of gays and lesbians $(r=-.20)$. Intense music preferences are associated with lower earnings per hour $(r=-.21)$ and also fewer working hours $(r=-.23)$. Intense music preferences are also negatively associated with overall well-being $(r=-.18)$. In terms of personality, intense preferences are positively associated with neuroticism $(r=.33)$ and negatively with agreeableness $(r=-.25)$.

\subsection{Contemporary}

The correlations for Contemporary music are shown in the last data column of Table 3. Metros with stronger preferences for Contemporary music are more affluent, with positive correlations to GRP per capita $(r=.30)$, income per capita $(r=.22)$, average wages $(r=.23)$, and wage per hour $(r=.25)$. These metros also have somewhat lower shares of working class $(r=-.20)$. Contemporary music metros have lower shares of white residents $(r=-.44)$, higher levels of black residents $(r=.30)$, as well as foreign-born people $(r=.26)$, and gays and lesbians $(r=.46)$. Married household also make up smaller shares of their population $(r=-.35)$. Politically, Contemporary music metros lean Democratic ( $r=.39$ to Obama votes) as opposed to Republican ( $r=-.39$ to Romney votes). There is a negative association to religiosity $(r=-.26)$. Contemporary music metros tend to be bigger in size ( $r=27$ with population). In terms of personality, contemporary music preferences are significantly associated with openness $(r=.25)$.

\section{Regression analysis}

We now move on to the multivariate OLS regression analysis. Since we only have 95 observations and a large number of explanatory variables, we first performed a principal component analysis to reduce the number of explanatory variables- the same technique that was used above when the music genres were generated. This allows us to reduce the number of variables to a limited number of extracted factor variables, which in turn reduces concerns about multicollinearity and degrees of freedom in the regression analysis. The new variables (factors) capture the metropolitan socioeconomic structures included in our study from a number of dimensions (Factor 1-7). Table 3 illustrates a summary of the seven extracted factor variables (a detailed table is provided in Table 9 Appendix). The extraction ranges from 0.595 to 0.918 and with an average of 0.796 .

The principle component analysis reduces the number of explanatory variables to seven factors, which are as follows.

Factor 1 This factor captures large affluent, diverse and creative metros. Metros in this group have larger populations, higher incomes, more highly educated 
populations, and higher levels of creative class workers. They have larger gay and bohemian populations and higher levels of well-being.

Factor 2 This second factor are metros with higher levels of Hispanic and foreign-born or immigrant populations. These metros also tend to have fewer singles, and they marry earlier in life. These metros also have relatively open personalities.

Factor 3 Metros with high factor 3 scores have a lower share of marriages, are more likely to vote Democratic in the latest election and less likely to be religious. These metros have relatively high levels of population density and lower shares of working class jobs.

Factor 4 This factor is closely related to the personality variables, and metros with high scores here are more agreeable and conscientious, but less neurotic.

Factor 5 This next factor is closely related to race, and metros with high Factor 5 scores have higher shares of black population and lower shares of white population.

Factor 6 Metros with high Factor 6 scores tend to work more hours per week and have higher divorce rates.

Factor 7 This last factor is most strongly related to the share of extroverts in the metro. It is also negatively related to the share of neurotic individuals.

We now move on to the OLS regression analysis to further examine to what extent the factors are related to our five music preferences as Table 4 shows:

Table 4 OLS Regression Results

\begin{tabular}{|c|c|c|c|c|c|}
\hline \multirow{2}{*}{$\begin{array}{l}\text { Indicator } \\
\text { Factor }\end{array}$} & \multicolumn{5}{|c|}{ Music-preference factors } \\
\hline & M & $\mathrm{U}$ & $\mathrm{S}$ & I & $\mathrm{C}$ \\
\hline Factor 1 & $0.008(0.150)$ & $\begin{array}{r}-0.296 * * \\
(-6.406)\end{array}$ & $0.206 * *(3.451)$ & $\begin{array}{l}-0.121 * \\
\quad(-2.177)\end{array}$ & $\begin{array}{l}0.157 * * \\
\quad(2.862)\end{array}$ \\
\hline Factor 2 & $0.470 * *(9.269)$ & 0.047 (1.019) & $0.040(0.664)$ & $\begin{array}{l}-0.092 \\
(-1.641)\end{array}$ & $0.051(0.928)$ \\
\hline Factor 3 & $\begin{array}{l}-0.053 \\
\quad(-1.056)\end{array}$ & $\begin{array}{r}-0.385^{* *} \\
(-8.339)\end{array}$ & $0.021(0.357)$ & $0.017(0.307)$ & $\begin{array}{l}0.244 * * \\
\quad(4.451)\end{array}$ \\
\hline Factor 4 & $\begin{array}{l}-0.028 \\
\quad(-0.553)\end{array}$ & $0.265 * *(5.736)$ & $0.120 *(2.020)$ & $\begin{array}{r}-0.077 \\
(-1.382)\end{array}$ & $0.108(1.969)$ \\
\hline Factor 5 & $\begin{array}{l}-0.128 * \\
\quad(-2.528)\end{array}$ & $0.255^{* *}(5.509)$ & $0.053(0.892)$ & $\begin{array}{r}-0.161 * * \\
(-2.878)\end{array}$ & $\begin{array}{l}0.202 * * \\
(3.679)\end{array}$ \\
\hline Factor 6 & $\begin{array}{r}-0.037 \\
\quad(-0.733)\end{array}$ & $0.079(1.708)$ & $0.044(0.738)$ & $0.098(1.750)$ & $\begin{array}{l}0.133 * \\
\quad(2.434)\end{array}$ \\
\hline Factor 7 & $0.096(1.893)$ & $\begin{array}{l}-0.007 \\
\quad(-0.151)\end{array}$ & $\begin{array}{r}-0.096 \\
(-1.606)\end{array}$ & $\begin{array}{r}-0.057 \\
\quad(-1.018)\end{array}$ & $0.530(0.966)$ \\
\hline Constant & $0.304 * *(6.040)$ & $\begin{array}{r}-0.303 * * \\
(-6.589)\end{array}$ & $0.142 *(2.400)$ & $\begin{array}{r}-0.236 * * \\
(-4.257)\end{array}$ & $0.096(1.771)$ \\
\hline$R^{2}$ & 0.529 & 0.671 & 0.191 & 0.201 & 0.379 \\
\hline $\mathrm{N}$ & 95 & 95 & 95 & 95 & 95 \\
\hline
\end{tabular}

$* p<.05, * * p<.01$ 


\subsection{Mellow}

Mellow music is most strongly positively associated with Factor 2 and negatively associated with Factor 5. Taken together, these two factors explain more than half of the variation in the mellow music. That means, mellow music is mainly associated with racial and ethnic characteristics. It is associated with higher shares of white, Hispanic and foreign-born populations and lower levels of blacks. It is also associated with places where people marry earlier and have more open personalities.

\subsection{Unpretentious}

Unpretentious music is related to four factors, two positively (Factors 4 and 5) and two negatively (Factors 1 and 3). Taken together, these factors explain $67 \%$ of the variation in unpretentious music. The strongest association is to Factor 3. Overall, unpretentious music is associated with more working class jobs, higher levels of political conservatism, lower levels of density, and higher levels of religiosity. The remaining three factors have associations of essentially similar magnitudes, whether positive or negative. Unpretentious music is also associated with lower levels of income, lower levels of college graduates, and smaller shares of creative class jobs; lower shares of gays and artists; and higher shares of black population and lower shares of white population. In terms of personality types, they also tend to more agreeable and conscientious.

\subsection{Sophisticated}

Sophisticated music is most strongly related to Factor 1. It is associated with higher levels of income and education, higher shares of the creative class, and higher levels of density. Sophisticated music is weakly but significantly related to Factor 4, which includes agreeable and conscientious personalities. These factors explain less of the variation in Sophisticated music than in the first two cases. In this case, the $R^{2}$ is only 0.191 .

\subsection{Intense}

Intense music is negatively related to two factors (Factors 1 and 5). It is more strongly and negatively related to Factor 5, indicating that intense music is associated with higher shares of white population and lower shares of black population. It is also negative and weakly related to Factor 1, meaning that intense music is associated with lower levels of income and education, smaller shares of the creative class jobs, lower levels of artists and gays, and lower levels of overall wellbeing. Together, these two factors explain roughly $20 \%$ of the variation in Intense music preferences. 


\subsection{Contemporary}

Contemporary music is related to four factors (Factors 1, 3, 5 and 6). These factors explain approximately $40 \%$ of the variation in contemporary music preferences across metros. Of these it is most closely related to Factor 3. Contemporary music is thus associated with higher levels of income and college grads, greater shares of the creative class and lower shares of the working class, higher levels of political liberalism, higher levels of density, and higher shares of artists and gays. Table 5 summarizes the results from the regression results by combining Tables 3 and 4:

\section{Discussion and conclusions}

Our research was based on the basic hypothesis that geographic differences in music preferences would reflect underlying economic and political divisions in American society. Our findings provide significant support for this hypothesis.

Broadly speaking of the five broad musical types, two-sophisticated and contemporary-are associated with more affluent, more educated, more knowledge based, more liberal, more diverse and denser places. Two others-unpretentious and intense-are associated with less advantaged, less educated, more working class, more conservative, and less diverse or whiter places. One remaining type, mellow music - is mainly associated with race and ethnicity, than class or economics.

Table 5 Factors and regression results

\begin{tabular}{|c|c|c|}
\hline Factor & Descriptive of factor & $\begin{array}{l}\text { Related to music-preference } \\
\text { dimension }\end{array}$ \\
\hline 1 & $\begin{array}{l}\text { Affluent, knowledge based, creative, diverse, population } \\
\text { dense }\end{array}$ & $\begin{array}{l}\text { Unpretentious }(-) \\
\text { Sophisticated }(+) \\
\text { Contemporary }(+) \\
\text { Intense }\end{array}$ \\
\hline 2 & $\begin{array}{l}\text { More Hispanics and foreign born, marries early, many single } \\
\text { households }\end{array}$ & Mellow (+) \\
\hline 3 & Democrats, less religious, lower shares of marriage & $\begin{array}{l}\text { Unpretentious }(-) \\
\text { Contemporary }(+)\end{array}$ \\
\hline 4 & Agreeable and conscientious, but less neurotic & $\begin{array}{l}\text { Unpretentious }(+) \\
\text { Sophisticated }(+)\end{array}$ \\
\hline 5 & More blacks and fewer whites. & $\begin{array}{l}\text { Unpretentious }(+) \\
\text { Contemporary (+) } \\
\text { Intense (- ) } \\
\text { Mellow (- ) }\end{array}$ \\
\hline 6 & Higher divorce shares and work more hours & Contemporary $(+)$ \\
\hline 7 & Extroverts & - \\
\hline
\end{tabular}


These results broadly track and reflect America's more basic political and economic divide, where more affluent, educated, knowledge based, denser and more diverse places trend liberal and less advantaged, less educated, working class, whiter, and more religious places trend conservative. We can say that broadly speaking musical preferences line up with these lines of class and political cleavage. Places where people prefer sophisticated and contemporary music are more affluent educated and liberal. Places where people prefer unpretentious and intense music are less advantaged, more working class and more conservative. Geographically, our preferences for music reflect and reinforce our political-economic divides.

Several caveats should be kept in mind in considering these findings and results. For one, they are based on a sample of self-selected participants who completed a self-report survey on the Internet. It could be that the individuals who volunteered to complete a survey about their music preferences may be more committed to music than the average person, so data based such participants may not be representative. That said, research on Internet-based studies indicates that Internet users are not perfectly representative of the general population (Lebo 2000; Lenhart 2000), but Internet-based samples are much more diverse and considerably more representative than the convenience samples commonly used in social science research (Birnbaum 2004; Gosling et al. 2004; Skitka and Sargis 2006). Furthermore, similar results are typically obtained across Internet and non-Internet samples, including studies of music preferences (Rentfrow et al. 2011, 2012; Rentfrow and Gosling 2003), and Internet-based studies tend to yield data that are comparable or of better quality than studies relying on paper and pencil, face-to-face, and telephone surveys (Richman et al. 1999; Skitka and Sargis 2006).

Still, our findings and results align previous research on cultural preferences more broadly. They are similar to the divides found by Zelinsky (1974) and Weiss (1988). Interestingly, given the fact that these studies were conducted several decades ago, it appears that these cultural divides are long-standing and deeply ingrained in America's political-economic and geographic divides. The similarly between the current findings and those from previous research suggests that our results are robust.

We hope that our research stimulates future research on this topic. Future research could obtain music-preference data for a nationally representative sample to evaluate the generalizability of the current results to other samples. Additionally, it would be useful to map music preferences using behaviorally revealed musicpreference information. Geographic information on music sales, digital downloads, or listening data from music-based online social networks would provide compelling data to compare with the current results. We look forward to more research on this important subject.

Open Access This article is distributed under the terms of the Creative Commons Attribution 4.0 International License (http://creativecommons.org/licenses/by/4.0/), which permits unrestricted use, distribution, and reproduction in any medium, provided you give appropriate credit to the original author(s) and the source, provide a link to the Creative Commons license, and indicate if changes were made.

\section{Appendix}

See Tables 6, 7, 8 and 9 . 
Table 6 Descriptive statistics for music genres

\begin{tabular}{llllll}
\hline & $N$ & Minimum & Maximum & Mean & SD \\
\hline Alternative & 95 & 4.67 & 5.52 & 5.19 & 0.13 \\
Bluegrass & 95 & 2.47 & 3.61 & 3.07 & 0.23 \\
Blues & 95 & 3.52 & 4.52 & 3.98 & 0.18 \\
Classical & 95 & 3.86 & 4.82 & 4.36 & 0.19 \\
Country & 95 & 2.81 & 4.06 & 3.36 & 0.23 \\
Electronica & 95 & 3.64 & 4.46 & 4.04 & 0.17 \\
Folk & 95 & 2.83 & 3.94 & 3.40 & 0.20 \\
Funk & 95 & 3.30 & 4.05 & 3.62 & 0.14 \\
Gospel & 95 & 2.36 & 3.41 & 2.79 & 0.19 \\
Heavy metal & 95 & 3.43 & 4.45 & 3.88 & 0.19 \\
Jazz & 95 & 3.53 & 4.56 & 4.07 & 0.18 \\
New age & 95 & 3.12 & 3.95 & 3.52 & 0.14 \\
Opera & 95 & 2.47 & 3.28 & 2.84 & 0.18 \\
Pop & 95 & 4.11 & 4.79 & 4.41 & 0.13 \\
Punk & 95 & 3.64 & 4.50 & 4.23 & 0.15 \\
Rap & 95 & 3.11 & 4.37 & 3.68 & 0.19 \\
Reggae & 95 & 3.41 & 4.40 & 3.76 & 0.18 \\
Religious & 95 & 2.12 & 3.51 & 2.74 & 0.31 \\
Rock & 95 & 5.51 & 6.16 & 5.86 & 0.12 \\
Soul & 95 & 3.57 & 4.49 & 3.98 & 0.18 \\
World & 95 & 3.20 & 4.25 & 3.60 & 0.20 \\
\hline & & & & &
\end{tabular}


Table 7 Five varimax-rotated principal components for individuals and for regions (based on the regional average scores)

Primary positively signed factor loadings are highlighted in bold. $N=96$

$M$ mellow, $U$ unpretentious, $S$ sophisticated, I intense, $C$ contemporary

\begin{tabular}{|c|c|c|c|c|c|}
\hline \multirow{2}{*}{ Genre } & \multicolumn{5}{|c|}{ Music-preference factors } \\
\hline & M & $\mathrm{U}$ & $\mathrm{S}$ & I & $\mathrm{C}$ \\
\hline Electronica & 0.80 & -0.08 & -0.07 & -0.03 & 0.42 \\
\hline New age & 0.73 & 0.38 & -0.27 & 0.00 & -0.17 \\
\hline Religious & 0.06 & 0.93 & 0.04 & -0.15 & -0.03 \\
\hline Country & 0.04 & 0.90 & 0.07 & 0.02 & 0.03 \\
\hline Gospel & 0.01 & 0.70 & 0.45 & -0.24 & 0.27 \\
\hline Pop & 0.36 & 0.49 & -0.14 & -0.42 & 0.39 \\
\hline Folk & 0.01 & -0.09 & 0.89 & -0.02 & -0.20 \\
\hline Bluegrass & -0.02 & 0.33 & 0.86 & -0.01 & -0.03 \\
\hline Blues & -0.02 & 0.25 & 0.85 & 0.10 & 0.27 \\
\hline Jazz & 0.15 & -0.01 & 0.81 & -0.07 & 0.33 \\
\hline Opera & 0.52 & 0.10 & 0.73 & 0.02 & 0.13 \\
\hline Classical & 0.65 & 0.15 & 0.66 & 0.09 & -0.03 \\
\hline World & 0.57 & -0.30 & 0.64 & -0.11 & 0.22 \\
\hline Heavy metal & 0.01 & 0.09 & -0.20 & 0.86 & -0.26 \\
\hline Rock & -0.30 & -0.13 & 0.30 & 0.74 & -0.25 \\
\hline Punk & 0.27 & -0.48 & -0.16 & 0.72 & 0.02 \\
\hline Alternative & 0.42 & -0.20 & 0.37 & 0.48 & 0.06 \\
\hline Rap & 0.04 & 0.12 & -0.18 & -0.21 & 0.87 \\
\hline Soul & 0.10 & 0.24 & 0.26 & -0.27 & 0.78 \\
\hline Funk & 0.07 & -0.06 & 0.60 & 0.09 & 0.64 \\
\hline Reggae & 0.26 & -0.23 & 0.41 & -0.06 & 0.63 \\
\hline
\end{tabular}


Table 8 Metro-level correlations between music preferences and socioeconomic indicators

Indicator Music-preference factors

$\mathrm{M} \quad \mathrm{U}$

S

I

C

Economic conditions and divides

GRP per capita

Income per capita

Average wage

Wage per hour

Hours per week

Class

Creative class

Working class

Human capital

Demographic

\section{Population and density}

Population

Population density

Race

Foreign born

Black population

White population

Hispanic population

Marital status

Single households

Married share

Divorce share

Married age 15-19 (M)

Married age 15-19 (F)

Political

\begin{abstract}
Obama votes
Romney votes
\end{abstract}

Psychology

Well-being

Openness

Religiosity

Bohemians

Gay index

Extraversion

Agreeableness

Conscientiousness

Neuroticism

-.127
$-.227 * *$
.020
.002
.115

$-.268 * * *$

$$
-.065
$$$$
\text { - .193* }
$$$$
-.559 * * *
$$$$
-.589 * * *
$$$$
-.436^{* * * *}
$$$$
.240 * *
$$

$.272^{* * *}$
$.218^{* *}$
.169
$.215^{* *}$
-.049

$-.111$

$-.097$

$-.205^{* *}$

$-.234 * *$

.058
$.342 * * *$
$-.201 * *$

$-.127$

$-.193^{*}$
$-.361 * * *$
$.480 * * *$

$.453 * * *$

.088

$-.370 * * *$
.122
$.381 * * *$
$-.299 * * *$

.118

$-.164$

$-.155$

$.266 * * *$

.000

.013

$-.209 * *$

$-.137$

.135

$.297 * * *$

$224 * *$

$.232 * *$

$.253 * *$

.118

$-.153$

$.257 * *$
- .196**

$-.386^{* * *} \quad .387 * * * \quad .134$

$-.218^{* *}$

$.347 * * *$

$.299 * * *$

$.009-.209 * *$

$-.033$

.004

$-.439 * * *$

.083

$-.617 * * *-.193 * * *$

.111

$.224 * *$

.122

$.304 * * *$

.123

$-.097$

.015

$-.348 * * *$

$183^{*}$

$.271 * * *$

$-.030$

$.275 * * *$

.044

$.399 * * *$

$.223^{* * * *}$

.057

.094

$-.042$

$.542 * * *$

$.401 * * *$

$-.010$

$-.039$

$-.051$

$-.043$

$-.535^{* * *}$

.081

$-.048$

$391 * * *$

.032

$.550 * * *$

$-.103$

.036

$-.387 * * *$

$\begin{array}{lcllc}.231 * * & -.090 & .361 * * * & -.175^{*} & .094 \\ .246 * * & -.162 & .325 * * * & -.135 & .251^{* *} \\ .063 & .799 * * * & .016 & -.061 & -.255^{* *} \\ -.082 & -.388^{* * *} & .323 * * * & -.050 & .149 \\ .214 * * & -.277 * * * & .434 * * * & -.203 * & .458 * * * \\ .008 & .140 & -.142 & -.020 & .043 \\ -.027 & .483 * * * & .054 & -.247 * * & .130 \\ -.070 & .482 * * * & .052 & -.029 & .078 \\ -.248 * * & -.093 & -.077 & .332 * * * & -.139\end{array}$

$M$ mellow, $U$ unpretentious, $S$ sophisticated, $I$ intense, $C$ contemporary

$* p<.05, * * p<.01, * * * p<.001, N=95$ 
Table 9 Seven Varimax-rotated Principal Components

\begin{tabular}{|c|c|c|c|c|c|c|c|}
\hline Factor variables & 1 & 2 & 3 & 4 & 5 & 6 & 7 \\
\hline \multicolumn{8}{|l|}{ Economic } \\
\hline GRP per capita & .834 & -.104 & .044 & -.082 & .194 & .045 & .050 \\
\hline Income per capita & .880 & -.223 & .188 & -.130 & .018 & -.020 & -.073 \\
\hline Average wage & .883 & .040 & .253 & -.158 & .088 & -.086 & -.099 \\
\hline Wage per hour & .833 & -.040 & .100 & -.228 & .148 & .045 & -.012 \\
\hline Hours per week & -.024 & .256 & -.263 & -.113 & .246 & .614 & -.095 \\
\hline \multicolumn{8}{|c|}{ Occupational and educational } \\
\hline Creative class & .884 & -.082 & .100 & .146 & -.038 & -.124 & -.155 \\
\hline Working class & -.575 & -.233 & -.422 & -.155 & .290 & .019 & .016 \\
\hline Human capital & .923 & -.161 & .050 & .072 & -.084 & -.144 & -.011 \\
\hline \multicolumn{8}{|l|}{ Demographic factors } \\
\hline Population & .494 & .203 & .336 & -.197 & .325 & .142 & .350 \\
\hline Population density & .505 & .351 & .408 & -.405 & .030 & -.137 & .146 \\
\hline Foreign born & .324 & .780 & .302 & -.234 & .061 & .006 & .049 \\
\hline Black population & -.059 & -.295 & .030 & .279 & .846 & .058 & .054 \\
\hline White population & -.210 & -.253 & -.161 & -.100 & -.874 & -.051 & .087 \\
\hline Hispanic population & -.163 & .910 & .207 & -.077 & -.102 & -.030 & .039 \\
\hline Single households & .075 & -.732 & .408 & -.039 & -.003 & .350 & -.047 \\
\hline Married share & .189 & .145 & -.741 & -.056 & -.496 & -.110 & .052 \\
\hline Divorce share & -.295 & -.266 & .005 & .144 & -.096 & .813 & .012 \\
\hline Married age $15-19(\mathrm{M})$ & -.256 & .762 & -.013 & .014 & .009 & -.016 & -.029 \\
\hline Married age 15-19 (F) & -.274 & .823 & -.283 & .102 & -.031 & .133 & -.060 \\
\hline \multicolumn{8}{|l|}{ Political divides } \\
\hline Obama votes & .257 & .050 & .857 & -.184 & .095 & -.141 & -.088 \\
\hline Romney votes & -.269 & -.058 & -.856 & .182 & -.072 & .133 & .102 \\
\hline \multicolumn{8}{|l|}{ Psychological } \\
\hline Well-being & .652 & .296 & -.133 & .155 & -.193 & -.333 & .017 \\
\hline Openness & .309 & .510 & .162 & -.001 & .096 & .379 & -.364 \\
\hline Religiosity & -.415 & .104 & -.655 & .237 & .366 & -.143 & .057 \\
\hline Bohemians & .637 & -.242 & .174 & -.080 & -.138 & .083 & .298 \\
\hline Gay index & .507 & .443 & .380 & -.037 & .107 & .346 & -.019 \\
\hline Extraversion & -.134 & -.078 & -.124 & .064 & -.022 & -.095 & .872 \\
\hline Agreeableness & -.064 & -.046 & -.140 & .799 & .246 & -.091 & .195 \\
\hline Conscientiousness & -.127 & -.061 & -.121 & .857 & .083 & .062 & -.073 \\
\hline Neuroticism & -.295 & -.235 & .144 & -.536 & -.010 & -.072 & -.557 \\
\hline
\end{tabular}




\section{References}

Birnbaum, M. H. (2004). Human research and data collection via the Internet. Annual Review of Psychology, 55, 803-832.

Bonneville-Roussy, A., Rentfrow, P. J., Xu, M., \& Potter, J. (2013). Music through the ages: Trends in musical engagement and preferences from adolescence through middle adulthood. Journal of Personality and Social Psychology, 105(4), 703-717.

Colley, A. (2008). Young people's musical taste: Relationship with gender and gender-related traits. Journal of Applied Social Psychology, 38, 2039-2055.

Delsing, M. J. M. H., Ter Bogt, T. F. M., Engels, R. C. M. E., \& Meeus, W. H. J. (2008). Adolescents' music preferences and personality characteristics. European Journal of Personality, 22, 109-130.

Dunn, P. G., de Ruyter, D., \& Bouwhuis, D. G. (2012). Toward a better understanding of the relation between music preference, listening behavior, and personality. Psychology of Music, 40(4), $411-428$.

Florida, R. (2002). The rise of the creative class. New York: Basic Books.

Fox, W. A., \& Wince, M. H. (1975). Musical taste cultures and taste publics. Youth and Society, 7(2), 198-224.

Gosling, S. D., Vazire, S., Srivastava, S., \& John, O. P. (2004). Should we trust web-based studies? A comparative analysis of six preconceptions about internet questionnaires. American Psychologist, 59, 93-104.

Katz-Gerro, T. (1999). Cultural consumption and social stratification: Leisure activities, musical tastes, and social location. Sociological Perspectives, 42, 627-646.

Lebo, H. (2000). The UCLA internet report: Surveying the digital future. Retrieved July 1, 2004, from University of California, Los Angeles, Center for Communication Policy Web site: http://www.ccp. ucla.edu/UCLA-Internet-Report-2000.pdf.

Lenhart, A. (2000). Who's not online: $57 \%$ of those without Internet access say they do not plan to log on. Retrieved July 1, 2004, from Pew Internet \& American Life Project Web site: http://www. pewinternet.org/reports/toc.asp?Report=21.

Lorenzo-Seva, U., \& ten Berge, J. M. F. (1977). Tucker's coefficient of congruence as a measure of factorial invariance: An empirical study (Heymans Bulletin No. 290 EX). Groningen, the Netherlands: University of Groningen.

Mark, N. (1998). Birds of a feather sing together. Social Forces, 77, 453-483.

McNamara, L., \& Ballard, M. E. (1999). "Resting arousal, sensation seeking, and music preference. Genetic, Social, and General Psychology Monographs, 125, 229-250.

Motion Picture Association of America, Inc. (2007). Entertainment industry market statistics. http:// www.mpaa.org/USEntertainmentIndustryMarketStats.pdf.

North, A. C., \& Hargreaves, D. J. (1996). Situational influences on reported musical preferences. Psychomusicology, 15, 30-45.

North, A. C., Hargreaves, D. J., \& McKendrick, J. (1999). The influence of music on in-store wine selections. Journal of Applied Psychology, 84, 271-276.

Rentfrow, P. J., Goldberg, L. R., \& Levitin, D. J. (2011). The structure of musical preferences: A fivefactor model. Journal of Personality and Social Psychology, 100, 1139-1157.

Rentfrow, P. J., Goldberg, L. R., Stillwell, D. J., Kosinski, M., Gosling, S. D., \& Levitin, D. L. (2012). The song remains the same: A replication and extension of the MUSIC model. Music Perception, 30, 161-185.

Rentfrow, P. J., \& Gosling, S. D. (2003). The do re mi's of everyday life: The structure and personality correlates of music preferences. Journal of Personality and Social Psychology, 84, 1236-1256.

Rentfrow, P. J., \& Gosling, S. D. (2006). Message in a ballad: The role of music preferences in interpersonal perception. Psychological Science, 17, 236-242.

Richman, W. L., Kiesler, S., Weisband, S., \& Drasgow, F. (1999). A meta-analytic study of social desirability distortion in computer-administered questionnaires, traditional questionnaires, and interviews. Journal of Applied Psychology, 84, 754-775.

Skitka, L. J., \& Sargis, E. G. (2006). The internet as a psychological laboratory. Annual Review of Psychology, 57, 529-555.

Van Eijck, K. (2001). Social differentiation in musical taste patterns. Social Forces, 79, 1163-1184.

Weiss, M. J. (1988). The clustering of America. New York: Harper \& Row. 
Zelinsky, W. (1974). Selfward bound? Personal preference patterns and the changing map of American society. Economic Geography, 50, 144-179.

Zweigenhaft, R. L. (2008). A do re mi encore: A closer look at the personality correlates of music preferences. Journal of Individual Differences, 29, 45-55. 